\title{
Autopilot in Not
}

\section{Liebe Leserin, lieber Leser,}

ein Tesla-Fahrer starb, während der Autopilot eingeschaltet war und das Fahrzeug mit einem Lkw zusammenstieß. So tragisch der Unfall auch war, er war sozusagen vorprogrammiert. Irgendwann musste es mal geschehen, wie Autoexperten im Vorfeld einräumten und damit eine Diskussion um ethische Betrachtungen initiierten.

Verkehrsminister Alexander Dobrindt gründet nun eine Ethik-Kommission. Diese soll Regeln für Algorithmen entwickeln, die bestimmen, wie ein Fahrzeug in einer Risikosituation reagiert. Er hält damit weiterhin an Plänen fest, noch 2016 eine - wie es heißt - innovationsfreundliche Änderung des Straßenverkehrsgesetzes zu beschließen. Vollautomatisiertes Fahren wäre dann in Deutschland zugelassen.

„Die Lust an der Innovation ist ein Wahnsinn“, wertet der Zukunftsforscher Paul Saffo, einer der prominentesten Deuter des Silicon Valleys im Magazin Brandeins. Er hinterfragt, ob die Innovationen auf dem Digitalisierungsfahrplan, den reiche Industrien und angebliche Gutmenschen vorgeben, gesellschaftlich überhaupt langfristig akzeptiert werden. „Wir stehen an der Schwelle zu einer neuen, weitgehend unbekannten Welt.“

Nicht vorhersehbar ist zum Beispiel der Ausgang der Debatte um ethische Fragen. Sie wird ernsthafter und differenzierter geführt werden müssen als bisher. Beispielsweise sollte sich die Autoindustrie Kritikerinnen wie Sarah Spiekermann stellen, einer Professorin für Betriebswirtschaftslehre und Wirtschaftsinformatik an der Wirtschaftsuniversität Wien. Sie will nicht Maschinen das Gute lehren, sondern dem Programmierer, wie sie in Brandeins erklärt. Entwickler steckten mit ihrer Verantwortung in einer unglücklichen Position: „Zurzeit verkaufen IT-Analysten
Zukunftsprognosen, wie es ihnen gerade passt. Wenn dann Führungskräfte nicht in der Lage sind, Realität von Fiktion zu unterscheiden, sind sie schlechte Führungskräfte.“ Die Professorin mahnt in diesem Zusammenhang: „Leute, die den Menschen als Systemfehler bezeichneten, wären fundamental respektlos. Wenn ich in einem vom Google-Rechenzentrum ferngesteuerten Auto sitze, dann sollte ich mich mit deren Menschenbild auseinandergesetzt haben.“

Von einer anderen Auseinandersetzung reden Piloten, die Flugzeuge automatisiert steuern lassen - und dies ständig überwachen müssen. Die Aufgabe des Fliegens sei wesentlich komplexer geworden. Man müsse dabei Maschine und Algorithmen verstehen. In komplexeren Verkehrssituationen setzen sich vergleichsweise ungeübte Fahrer eines Tesla, eigentlich Amateure, über Warnhinweise im Autopilot-Modus hinweg. Dass sie das heute schon können, macht nachdenklich. Ethisch bedenklich? Was meinen Sie?

Herzliche Grüße

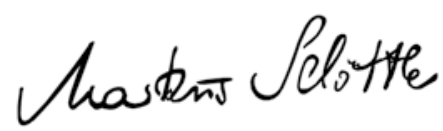

Markus Schöttle

Stellvertretender Chefredakteur

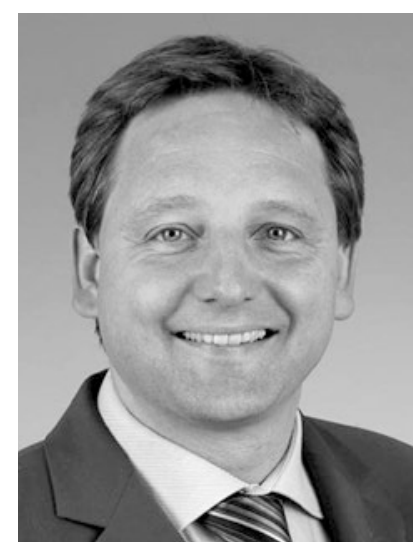

May 17th - 18th, 2017 in Bamberg, Germany
Electric \& Electronic Systems in Hybrid and Electrical Vehicles and Electrical Energy Management

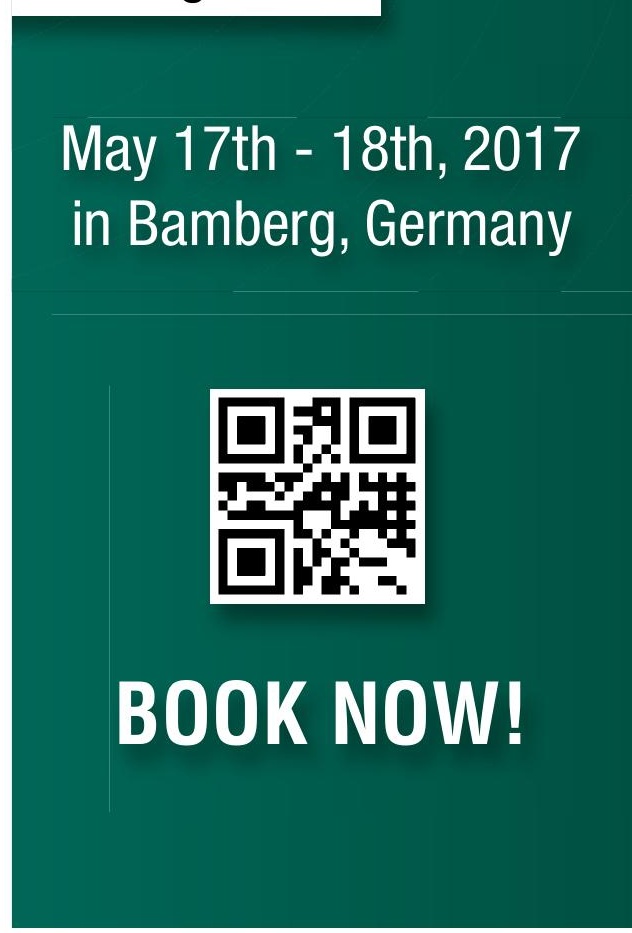

Further information: 